\title{
A Re-investigation of the Concept of Word Classes Through a Categorization Approach
}

\author{
Osondu C. Unegbu \\ Nigeria Police Academy, Wudil, Kano State, Nigeria
}

\begin{abstract}
The concept of word classes (parts of speech) has always generated controversy among linguists. The earlier Prescriptive and Descriptive Schools might have set the pace for this controversy but the present dilemma is much deeper. Learners and even teachers are sometimes at quandary as to how to proof that a particular word belongs to a particular class. This is because a word may sometimes belong to several classes, in context as in the word "watch" which can belong to different classes. This paper therefore tries to provide answers to the problem of word class classification by using a morphological and syntactical evidence to prove that English words follow a particular range of inflections and belong to strictly ordered particular categories and do not change their class arbitrarily. This is in line with the natural perfect order of homogeneity in creation which precludes a specie from merging effectively with another specie without having to undergo some fundamental changes. Other variables were also looked into and it was concluded that teachers and learners as well, can rely on this sub-categorization approach as a reliable paradigm for their assumptions concerning word classes.
\end{abstract}

Keywords: categorization, substitution, classification, sub-categorization, inflection, morpho-syntactic

\section{Introduction}

This work was motivated by the desire to contribute to the difficulty in placing the English word classes properly according to their grammatical categories. This is because over the years, it has been discovered that a word can belong to different classes like noun, verb, adjective, etc. in context. This definitely, will always create learning difficulties to learners if not properly addressed. Moreover, some words cannot be easily placed as belonging to a class as according to Kersty and Kate (2010), it is a matter of degree as s/he made the following observations: “There are prototypical sports like 'football'; and not sporty sports like 'darts'”. There are exemplary mammals like "dogs" and freakish ones like "platy pus". Similarly, there are good exemplary verbs like "watch" and lousy examples like "beware". Exemplary nouns like "chair" that display all the features of a typical noun and some not so good ones like "Kenny".

It is therefore based on the above issues and my understanding of the natural ordering in creation that the author makes this research on English word classes. Since it is an established fact that two different species in creation cannot naturally mix (for instance) water and kerosene or a dog and a fish, also in language, the author believes that there must be some strictly ordered criteria for placing words in their different categories despite the difficulty. Grammar is a linguistic category which is generally defined by its syntactic or morphological behaviour. Therefore, we are going to look at the eight traditionally known parts of speech through a 
morpho-syntactic process of analysis. However, the term word classes will henceforth be used in this write up since it conforms more closely to our categorization process. Also to buttress this point, David (2003) states that:

When linguist began to look closely at English Grammatical structure in the 1940's and 1950's they encountered so many problems of identification and definition that the term parts of speech soon fell out of favour, word class being introduced instead. Word classes are equivalent to parts of speech but defined according to strict linguistic criteria. (p. 3)

\section{The Evolution of English Word Classes}

The English language was in the medieval period (about 5th-15th Century AD), the language of peasants while Latin and other Classical Languages were the languages of learning. However, as from the Renaissance period (about 14th-17th Century AD), English became a pre-eminent language in Europe over the Classical Languages mainly due to the colonization policy of Great Britain. Therefore, it is not surprising that the early English grammar had Latin origin which was rule governed and this gave rise to the early theory of grammar as Prescriptive Grammar (PG) (also called Traditional Grammar-TG). This theory believes in prescribing usage rules for learners. These greatly influenced the early English grammarians since they followed the earlier Traditional Grammarian's approach. An analysis of some grammatical theories will suffice.

\section{The Prescriptive or Traditional Grammar}

The PG grammar was referred to as "text-book grammar" because of its strict adherence to rules. The grammar books then contained almost all the rules and were therefore rule-centered. Rule-centred Latin grammar formed the origin of "Prescriptive or Traditional Grammar". The prescriptive "Grammar School" is hinged on the principle of prescribing usage rules for speakers based on Latin rules because the "Traditionalists" strongly hold unto language universals, i.e., the notion that all languages share the same properties/characteristics. For instance, since Latin and Greek have eight parts of speech, other languages must also have eight. They also rely heavily on prescribed definitions of these parts of speech and anything that does not conform to their definitions is wrong. They equally emphasize writing over speech in language learning and rely heavily on memorization.

\section{Descriptive or Structural Grammar}

In view of this, around the 20th Century, modern linguists proclaimed their faults in the nature of each language as used by its native speakers in terms of prescribing usage rules. They have discovered that each language has its own set of rules of structure and usage and this is contrary to earlier practice. They posit that the job of a grammarian is not to make (prescribe) usage rules of a language. The grammarian should merely codify and explain what is already there, i.e., the usage of the people who speak the language. Each language must therefore be described according to its own rules and not according to the grammar of another language. This method of describing language is the second theory called "Descriptive or Structural Grammar" (D.G. or S.G.) and it is a counterpoise to the earlier school-Prescriptive or Traditional Grammar. The Descriptive Grammarians therefore do not subscribe to the idea of language universals because, according to them, the fact that languages have certain things in common does not necessarily mean that all languages are the same. They also believe strongly in the primacy of speech over writing in learning because apart from the fact that speech developed before writing, writing is considered as a special dialect of a language. They classified the English words into "grammatical/function" words and "content" words. For instance, grammatical words are those 
whose meanings cannot be established in isolation, i.e., when used alone and not in conjunction with other words. Here are some examples: the meanings of these words: and, on, etc. cannot be known except when they are used together with other words to form a sentence, as in: "my brother bought for me a book and a school bag". "I kept the book on the table”. They called these grammatical words "closed class items" because no new ones are being admitted into the English language. The closed items include: conjunctions, prepositions, adverbs, and interjections. On the other hand, the content words are those whose meanings can be deduced from the individual words in isolation. These are the nouns, pronouns, verbs, and adjectives (boy, she, run, tall). They called this set "open class items" because new words are being formed regularly from them. Lastly, Descriptive Grammarians do not agree on prescribing definitions for linguistic concepts, especially the parts of speech. Their stand is that instead of defining a noun or verb, one can describe them through their different components. Illustratively, this can be shown in the following sentences: "The boys are playing football”. The noun "boys" can be so identified because: (1) it is preceded by the determiner "the"; (2) it is plural because it has the plural suffix "s"; and (3) it can easily swap places with another noun, e.g., "The girls are playing football". They equally believe in the denotative and connotative meanings of words, as opposed to the Traditional Grammarian's “undifferentiated total meaning of words”. This kind of grammar describes the rules that can be used to produce all the sentences contained within a language.

\section{The Systemic Functional Grammar}

This theory of grammar was the brain child of a British linguist in the 1960s Halliday, who viewed language as a "network of systems" or "interrelated set of options for making meaning" (Halliday, 1994). He views language as being functional in the sense that it is as it is because of what it has evolved to do. Thus language being that which "reflects the multidimensional nature of human experience and interpersonal relations" (Halliday, 2003). Also, according to Robert (2007): "systemic linguistics (SL) is an avowedly functional approach to language and it is arguably the functionalist's approach which has been most highly developed". He further states that the most distinguishing feature of SL from other theories is that SL "explicitly attempts to combine purely structural information with overtly social factors in a single integrated description". Furthermore, Robert made us to understand that SL is deeply concerned with the purpose of language use and systemicists constantly ask the following questions: "what is the writer or speaker trying to do? What linguistic devises are available to help him do it and on what basis do they make their choices"?

In the light of the above, this write up on word classes is going to be based on a systemic approach since it shares the same concerns with it.

\section{Some Divergencies Between the Prescriptive and Descriptive Grammar}

While the Traditional Linguists define a noun as the name of a person (Kate), place (Gamestown), animal (goat), or thing (car), the Descriptive Linguists claim that such definition is inadequate since it excludes abstract things like "beauty, truth", etc.. They redefine a noun as a naming word or, the name of a person, place, animal, thing, and abstract qualities. Or simply put: The noun is a naming word. This divergence also extends to the verb. While the traditional Linguists define it as a doing word, the modern Descriptive Linguists consider it inadequate because it tends to ascribe to the verb only the role of action, whereas in the actual sense, a verb describes both actions, processes, and state of being (c.f. I believe in you. He is not a good man. This is my friend). The descriptive Grammarians therefore redefine a verb as a word that shows action and state of being.

On the adjective, there is also a divergence between the two schools. The Traditional Grammarians define 
it as: A word that modifies a noun (e.g., a brick wall). However, the Modern Grammarians point out that some adjectives can perform a dual role of belonging to both the noun and the adjective. For instance, in the above sentence: "give me a brick", "brick" is an adjective, but can also be a noun in another sentence like: "I need a brick". So according to the descriptive linguists, an adjective is a word that modifies and can be modified.

In as much as the two schools which do not necessarily disagree on the other traditionally known English word classes, there are other areas of divergence between them. For instance, prescriptive grammar accepts sentences like this: “To whom are you talking?” This is because "who are you talking to?” (which the Modern Grammarians accept), ends with a preposition "to" (and the rule of Prescriptive Grammar rejects it). Also Prescriptive Grammar accepts this form: "It is I” instead of the Modern Grammarian’s “It is me”. They claim that a linking verb "is", takes another word only in the nominative (subject) and not in the accusative (object) position. But the Descriptive Grammarians argue that even though "me" is in the objective case, it is the current usage of the owners of the language.

Lastly, Traditional Grammar says that an infinitive should not be split, e.g., "I want you to clearly understand", i.e., the infinitive "understand", is split by the adverb "clearly". The preferred form here is: "I want you to understand clearly”. On the other hand, The Modern Descriptive Grammarians say that one can split an infinitive.

\section{Difficulties in Previous Categorization Process}

Since the earliest prescriptive Grammar era, parts of speech have been defined by morphological, syntactical, and semantic criteria, i.e., according to their inflectionary changes, rules, and meaning respectively. However, it has been difficult to come up with a generally agreed upon criteria for the classification of these parts of speech. This may not be unconnected with the fact that words do not belong to one part of speech as earlier pointed out. On this, Sidney (1996) says:

look is a verb in "it looks good" but a noun in "she has good looks", that is a conjunction in "I know that they are abroad" but a pronoun in "I know that" and a determiner in "I know that man". One is a generic pronoun in "one must be careful not to offend them" but a numeral in "give me one good reason". (p. 4)

However, this problem of classification has continued even up to today. This is because linguistic items may belong to many classes and even when used in context, ambiguity can still arise. This is because even though we recognize the class of words in context, some words still are difficult to be categorised, especially those that end with suffixes. To this Sidney and Gerald (2009), say:

ly is a typical suffix for adverbs (slowly proudly), but we also find this suffix in adjectives cowardly, homely, manly. And we can sometimes convert words from one class to another even though they have suffixes that are typical of their original class, an engineer, a negative response, a negative. (p. 84)

The problem of classification is even much deeper in terms of affixations. This is because certain word classes take particular inflectional changes to change their class as in the ly adverb marker (hungrily, adversely, beautifully, etc.). However, it is a fact that not all adverbs end in ly suffix as in: fast, wise, yesterday, etc. While some classes that take the ly suffix are actually adjectives, as in: friendly, manly, etc. and some that take the ly can belong to either the adjective or adverb as in: lively—a lively joke/man (adjective); She danced very lively (adverb). Therefore, any such strict categorization based on affixation will fail. In other to come out of this problem, some linguists like Martha and Robert (1998), have classified words according to their function like 
the open class items (nouns, verbs, adjectives, adverbs, and interjections) and closed class items (auxiliary verbs, conjunctions, pronouns, prepositions, etc.). This too cannot effectively categorize words according to their classes. This is because some linguists like kroeger (2005) have argued that this type of classification is inadequate since the eight word classes are "greatly simplified and artificial". According to him, "adverb is to some extent a catch—all class that includes words with many different functions" (p. 35).

\section{The Categorizations Approach-The Verb}

In English, verbs take a characteristic range of inflections like "ing - s - ed", giving us paradigms like: Like - liking - likes - liked

Kiss - kissing - kisses - kissed

Play - playing - plays - played

Drive - driving - drives - drove (irregular verb).

By contrast, nouns do not permit the same range of verbal inflections, c.f. Boy *boying - boys - boyed (N.B: a star before a word or sentence indicates incorrectness)

People *peopling - peoples - peopled

Book *booking - books - booked.

It is interesting to note that the only inflection permitted by the verb and the noun together is the "s" suffix. But while the addition of "s" to a noun indicates plurality, (as in boys), "s" in a verb indicates singularity and also that the subject of the verb is singular in relation to the subject-verb agreement (as in the boy plays). The other corresponding inflections like "booking, booked" change the word category from verb to noun. This justifies the intuition that such morphological inflections like - "ing - ed" etc. belong only to the verb.

Also c.f. Prepositions: At - *ating - ats - ated

On - *oning - ons - oned etc.

Pronouns: He - *heing - hes - heed

They - *theying - theys - theyed

She - *sheing - shes - sheed

Us - *using - uss - used

Adjectives: Huge - *hugeing - huges - hugeed

Fat $-*$ fating - fats - fated

Adverbs: Yesterday - *yesterdaying - yesterdays - yeserdayed

Hungrily - *hungrilying - hungrilys - hungrilyed

Conjunctions: And - *anding - ands - anded

But - *buting - buts - buted

Interjections: Oh! - *ohing! - ohs! - ohed!

Ah! - *ahing! - ahs! - ahed!

\section{The Noun}

Only nouns take the following range of morphological inflections:

Boy - boys - the boy - a boy

Egg - eggs - the egg - an egg

Secondly, only nouns can occupy the same syntactical positions, i.e., successfully swap places with other nouns without distorting the meaning, c.f. The boy is my brother: 
*The play is my brother

*The he is my brother

*The fast is my brother

*The huge is my brother

*The in is my brother

*The ah! is my brother

Likewise, only noun phrases can take a genitive "s" inflection, as in: Aminu's book, the driver's car, that rich man's brother, the Queen's jewelry, the Queen of England's son, etc.

The same range of genitive inflections cannot go with adverbial phrases, c.f. *very slowly's, rather too slow's, too fast's, very hungrily's, much too soon's, etc.

The same exclusion is on the other word classes, c.f. *I's, at's, our's, your's, and's, ah's!, huge's, etc.

Furthermore, the categorization of noun + "s" suffix (to form plurals, c.f. boy - boys) and being preceded by the determiners a, an \& the, is a property of the noun. This cannot go with the other parts of speech, c.f. Verb: Play - *plays - the plays - a plays (NB: the play and a play change the word class from verb to noun). Likewise: swim - the swim - a swim.

Prepositions: On - *ons - the on - a on

In - *ins - an in - the in - a in

It is noteworthy that "on" and "in" can syntactically swap positions with each other as in the nouns: "boy and egg”, but this will likely affect the sentence semantically, c.f. The boy is good.

The egg is good.

The book is on the table.

*The book is in the table.

Also for the verb: I play football everyday

*I swim football everyday

Also c.f. The boy plays football.

The boys play football.

NB: while the "s" suffix changes a noun to plural, it changes a verb to singular. This is further proof that it is only the noun that can effectively swap places with another noun without distorting the meaning. Furthermore, in as much as both the noun and the verb can take the "s" morphological inflection, it changes the number and case, from singular to plural (noun) and from plural to singular (verb). So it is only the noun that can be preceded by the determiners (a, an \& the) and also swap places with another noun and successfully take the "s" inflection to become plural. C.f. Pronoun:

He *hes - the he - a he - an he

Mine *mines - the mine - a mine - an mine

Adjectives: Long *longs - the long - a long - an long

Short *shorts - the short - a short - an short

Foolish: They are fools. *They are foolishes

NB: the adjective can accept the same range of determiners in some cases, c.f. a long road, a short man, an ugly cat, the merciless man.

This may not be unconnected with the fact that adjectives are related to the noun since it is the adjective that modifiers the noun. But when looked at critically, the determiner does not specify the adjective but the 
noun, since the adjective is just there to pre-modify the noun. So, the phrase is actually—the man (which one? The merciless man).

Adverbs: beautifully *beautifullys, the beautifully, a beautifully, an beautifully. NB: where the adverb accepts to be preceded by the determiners: a, an \& the, it changes it to adjective. C.f. A beautifully planned dance. The beautifully crafted cloth.

Conjunctions: And *ands - the and - a and - an and

Or * ors - the or - a or - an -or

Interjections: Ah! *ahs! - the ah! - a ah! - an ah!

\section{Adjectives}

In the same way, only adjectives accept (a subset) of a comparative inflectionary form in "er" morpheme, c.f. tall - taller, fat - fatter, lovely - lovelier, nice - nicer etc. and not nouns, c.f. boy - *boyer, girl - girler, cat - cater etc.

Verbs: Play - *player, (er morpheme changes verb to noun), run - *runner, eat - *eater, sit - *siter, read reader etc.

Prepositions: Behind - behinder, on - *oner, into - intoer, at - ater, etc.

Pronouns: I - *Ier, We - *weer, it - *iter, they - *theyer, etc.

Conjunctions: And - *ander, but - *buter, etc.

Adverbs: Hungrily - *hungrilyer, slow - *slower, etc.

NB: The "er" inflection seems to accord with both adjectives and adverbs, c.f.

He ran faster and won (adv.). However, the adverb will fail the substitution test and hence cannot be strictly categorized with the adjective, c.f. The faster man is here (adj.). An adverb cannot swap places without it still remaining an adjective, c.f. The slower man is here. It should also be noted that it is only in very limited number of adverbs that we can find the "er" morpheme corresponding with that of the adjective, as in "faster and slower".

Interjections: Ah! - *aher! - oher! - helloer!, etc.

\section{Adverbs}

One can rightly posit that only adverbs can morphologically add the "ly" inflection without the meaning being affected c.f. hungrily, slowly (adverbs). And not nouns: boy - *boyly - woman - *womanly, girl - *girly, etc. NB: when "ly" is affixed to some nouns: woman to womanly, girly, manly, they change from nouns to adjectives.

Verb: Play - *playly, sing - *singly, run - *runly, drive - drively. Also in following syntactic categorization, it is only an adverb that can effectively swap places with another adverb c.f. He ate the food hungrily. He ate the food greedily. No other word class can fit into the structure without affecting the meaning semantically, c.f. *He ate the food cat (noun). ${ }^{*} \mathrm{He}$ ate the food play (verb). $*$ He ate the food us (pronoun). *He ate the food and (conjunction). ${ }^{*}$ He ate the food at (preposition). ${ }^{*}$ He ate the food fat (adjective).

\section{Pronouns}

Still in following the categorization order, only pronouns are inflected for nominative (subject) and accusative (object) cases, (according to traditional Latin terminology), which gives rise to alternations like this: I - me; he - him; she - her; we - us; they - them. Whereas nouns, adjectives, verbs, adverbs, prepositions, conjunctions and interjections, by contrast, are not morphologically marked the same way, c.f. I gave it to him. 
He did it for me. She gave it to her. He did it for him. But not noun: *Aminu did it for Aminu (Verb) *Play the ball play. NB: Where a word belonging to the same class can be used in the nominative and accusative positions (as in the noun above), the noun "Aminu" is still not able to change its form from subject to object as in I - me, he - him, she - her, etc. For the other word classes, it is simply impossible since they don't have the quality of the pronoun to be categorized the same way.

\section{Prepositions}

In the same vein, one can rightly posit that only prepositions act as connectors between two elements, c.f. I saw him behind (from, into, in, on, at, inside, beside, etc.) the wall.

From the above examples, one preposition can rightly be substituted with another without seriously distorting the meaning. Where there is a disagreement, it is as a result of the misuse of prepositions in terms of its kind, i.e., where a preposition of place is used in place of a preposition of time, c.f. *I saw him from the house. But this is not the case with the other word classes when they are substituted in the same position as the preposition, c.f. I saw him behind the house.

*I saw him boy the house

*I saw him dance the house

*I saw him ah! the house

*I saw him long the house

*I saw him slowly the house, etc.

This further proves that words are grouped into closely-nit categories.

\section{Conjunctions}

Only conjunctions can function as a link between two words or two parts of a sentence, c.f. bread and butter. Aminu is a student but Amina is a trader. The old man and the woman are here.

In keeping with categorization order, other parts of speech cannot occupy the same position as the conjunction, c.f.

The doctor and the nurse are in the hospital

*The doctor boy the nurse are in the hospital

*The doctor play the nurse are in the hospital

*The doctor huge the nurse are in the hospital

*The doctor fast the nurse are in the hospital

*The doctor on the nurse are in the hospital

*The doctor I the nurse are in the hospital

*The doctor ah! the nurse are in the hospital.

\section{Interjections}

This seems to be an exception since most of the word classes can equally be used to show emotion or emphasis just as the traditional interjections, c.f. Ah! I was surprised.

Boy! I was surprised.

Play! I was surprised.

fat! I was surprised.

Besides! I was surprised.

fast! I was surprised. 
But! I was surprised.

He! I was surprised.

This failure of the substitution order on the interjection further reinforces the intuition that words belong to closely-nit syntactic categories. This is because most scholars like Morley (2000, p. 45), have pointed out that the interjection does not belong to the word class but to the interjection class. They claim that the main distinguishing feature of the interjection is the interjection mark (!). So it is not surprising that of all the other seven word classes analysed, it is only the interjection that violates this categorization process. I share the same view on interjection as a word class and suggest that it should be properly placed where it belongs - the punctuation class.

\section{Some Merits of This Approach}

To achieve an all-inclusive categorization of the word classes, this approach is based on three criteria namely: semantic, i.e., the meanings of the word, syntactic, i.e., the position of the word in a sentence based on grammatical rules and morphological, i.e., the type of inflectionary changes that are attached to a word.

Some merits of this approach can be seen from the perspective that it will allow us to place words appropriately according to their meaning. For instance, in the sentences: "My wife is a beautiful woman". And * "My house is a beautiful woman". We can intuitively sense that a house cannot at the same time be a beautiful woman since it is not human but an inanimate object, though both are nouns. On the other hand, it will allow us the leverage to effectively substitute words within a sentence with other words of a similar meaning, as in: "My daughter is a beautiful woman".

On the morpho-syntactical level, it has the merit of not allowing certain grammatical units to precede or come after some words, as in: *I bought car”, instead of the correct "I bought a car”.

This academic exercise is aimed at proving that words are strictly sub-categorized into different grammatical constituents (nouns, verbs, pronouns, etc.). This is achieved through morpho-syntactical evidence. It has been proved that in English, a specific type of inflection attaches to only a specific category of words. This approach tends to posit that words are hierarchically structured into constituents, assigned to various categories which also have independent morphological motivations.

To put it more succinctly, this categorization approach has the advantage of clearly explaining the meaning of words and through a substitution order, is able to place words appropriately according to their class. Lastly, words have been categorized appropriately based on their environment, i.e., the words that naturally occur before and after them. It is hoped therefore that this will go a long way in helping to place word classes more properly according to their categories without much difficulty.

\section{Conclusion}

Chomsky (1972) has proved that category based grammar is more constrained, i.e., structure dependent since it adheres strictly to the categorization, substitution, and morphological order. By being more constrained, a learner is assisted to recognize which word belongs to which category of the word class. C.f. determiners: I want a toy I want this toy

I want the toy

I want that toy

Nouns: I saw a man 
I saw a woman

I saw a girl

I saw a book etc.

Verbs: I played the ball

I kicked the ball

I threw the ball

I missed the ball etc.

Pronouns: I gave it to him

I gave it to her

I gave it to them

I gave it to us

*I gave it to our NB: a disagreement can only arise where there is a misuse of a kind of word class as in the case of "our" which is a possessive pronoun.

In essence, words don't just belong to classes arbitrarily. The assumption that words fit into categorized, syntactic, morphological rules, and that there is a highly restricted universal set of categories in natural languages; and the assumption that a learner either knows intuitively (innately), or learns these restrictions, provides a highly plausible model of language mastery in which languages become learnable in a relatively short period of time.

It is hoped that this little contribution to knowledge will go a long way in assisting both teachers and learners in mastering the English word classes without much difficulty.

\section{References}

Brown, K., \& Miller, J. (1992).A linguistic introduction to sentence structure. London:Routhledge. Chomsky, N. (1972). Language \& mind. New York: Harcourt Brace Jovanovich.

David, C. (2003). The Cambridge encyclopedia of the English language (2nd ed). Cambridge: Cambridge University Press. Halliday, M. A. K. (1994). Introduction to functional grammar (2nd ed.). London: Edward Arnold.

Halliday, M. A. K. (2003). On the "Architecture of human language”. London: Bloomsbury Academic. Kersty, B., \& Kate, B. (2010). Introducing English grammar (2nd ed.). London: Hodder Education. Kroeger, P. (2005). Analysing grammar: An introduction. London: Cambridge University Press. Lyons, J. (1979). Introduction to theoretical linguistics. London: University Press. Martha, K., \& Robert, F. (1998). Understanding English grammar. Boston: Allyn and Bacon. Morley, G. D. (2000). Syntax in functional grammar. London: Library of Congress Cataloging-in-Publication Data. Quirk, R., \& Sidney, G. (1980). A university grammar of English. London: Longman.

Radford, A. (1997). Syntactic theory \& the structure of English. London: Cambridge University Press.

Robert, L. (2007). Language and linguistics: The key concepts. London: Routledge.

Sidney, G. (1996). Oxford English grammar. Oxford: Oxford University Press.

Sidney, G., \& Gerald, N. (2009). An introduction to English grammar (3rd ed.). Harlow: Pearson. 